\title{
Increased serum and synovial fluid antibodies to immunoselected peptides in patients with rheumatoid arthritis
}

\author{
Anne Dybwad, Øystein Førre, Mouldy Sioud
}

\begin{abstract}
Objectives-To investigate the role of potential immunoselected phages displaying random peptides in addition to possible antigen leads in rheumatoid arthritis (RA) by assaying the levels of synovial fluid (SF) and serum antibodies to synthetic peptides.

Methods-Serum and SF antibodies from patients and controls were measured using an enzyme linked immunosorbent assay (ELISA).

Results-Sera and SF from RA patients reacted significantly more strongly to a 12 amino acid peptide, EFHELGDIAIAA, that shares a significant homology with collagen type $I X$, than did SF and sera from control groups $(p<0.0209$ and $p<0.0115$, respectively). In addition, the humoral responses to a 15 amino acid peptide, GGYGDGGAHGGGYGG, derived from the glycine-rich cell wall protein (GRP) $1 \cdot 8$, and to a 16 amino acid synthetic peptide, LGSISESRRALQDSQR, derived from the Proteus haemolysin protein were significantly stronger in RA patients compared with healthy individuals $(p<0.0001$ and p $<0.0011$, respectively).

Conclusion-Our data indicate that peptide phage libraries can be used as tools for the identification of the (auto)antigen leads that may be responsible for the initiation, perpetuation, or both, of the immune response in patients with RA.
\end{abstract}

(Ann Rheum Dis 1996; 55: 437-441)

Institute of

Immunology and Rheumatology,

University of Oslo, Oslo, Norway

A Dybwad

M Sioud

Oslo Sanitetsforening Rheumatism Hospital Oslo, Norway

$\varnothing$ Forre

Correspondence to: Anne Dybwad, Institute of Immunology and Rheumatology, University of Oslo, Fr Ovamst 1, Fr Qvamsgt 1, Norway.

Accepted for publication 6 March 1996
Rheumatoid arthritis (RA) is an autoimmune disease characterised by chronic inflammation of synovial membranes and synovial fluids (SF) in multiple joints. Although its pathogenesis remains unknown, both cellular and humoral autoimmune mechanisms have been implicated. ${ }^{1}$ The presence of a wide variety of circulating autoantibodies has been described, including rheumatoid factors and antibodies to nuclear or structural cellular components. ${ }^{2-4}$ In rheumatic pathologies, it is possible that many different arthritogenic stimuli may activate the immune response leading, for example, to RA. Among these stimuli, both viral and bacterial infections have been suggested to be involved. ${ }^{5}$ Following infection, these micro-organisms should be cleared by the immune system, and will therefore no longer be detectable during the chronic stage of the disease. However, the induction of the humoral response by such stimuli can be traced by identifying the specificities of their corresponding antibodies in the sera of the patients.

To examine this, we previously used a novel approach based on the screening of random peptide phage libraries with sera and SF antibodies from patients with $\mathrm{RA}^{6}{ }^{67}$ our rationale being that antibodies from a patient may bind to phages displaying peptides similar or identical to the peptides that initiated the disease. In the present study, we have investigated the $\mathrm{SF}$ and humoral responses of patients with RA and control groups to synthetic peptides displayed by immunoselected phages, and to peptides derived from potential antigen leads.

\section{Patients and methods}

PATIENTS

Sera were obtained from healthy blood donors and patients with RA. SF samples were collected from patients with osteoarthritis (OA) or RA who fulfilled the diagnostic criteria of the American College of Rheumatology. ${ }^{8}$

HUMORAL RESPONSE AGAINST AN

IMMUNOSELECTED PEPTIDE FROM A PHAGE

DISPLAY LIBRARY BY POLYCLONAL SF

ANTIBODIES

In a previous study we screened a random nine amino acid peptide library with polyclonal SF antibodies. ${ }^{7}$ Groups of peptides were identified, some of which shared the consensus sequence of GDIA that is present in many potential (auto)antigens (table 1). To characterise further the antibody response in patients with RA against such an immunoselected sequence, a 12 amino acid synthetic peptide (GDIA peptide: EFHELGDIAIAA) was made and its reactivity was investigated by enzyme linked immunosorbent assay (ELISA).

HUMORAL RESPONSE IN PATIENTS WITH RA AGAINST A GLYCINE-RICH CELL WALI PROTEIN DERIVED PEPTIDE

A nanopeptide immunoselected by sera from patients with RA (pep1: ADGGAQGTA) was used previously as an indicator to identify cereal glycine-rich cell wall proteins (GRPs) 
that share significant homology with human cytokeratins and the Epstein-Barr virus nuclear antigen-1 (EBNA-1)..$^{9}$ In order to investigate possible involvement of the GRPs in the pathogenesis of RA, a 15 amino acid synthetic peptide (GRP peptide: GGYGDGGAHGGGYGG) corresponding to position $418-432$ in the GRP 1.8 protein ${ }^{10}$ was synthesised and its reactivity with sera from patients with $R A$ was investigated.

The GRP peptide has a significant homology with a peptide sequence present within human epidermal keratin (EPK) at position 568-582 (GGYGSGGGSGGRYGS: bold letters indicate the sequence homology with the GRP peptide), thus antibodies to these proteins could potentially be cross reactive. To examine this, we first tested the humoral response to EPK of 20 GRP peptide positive patients with $\mathrm{RA}$, then tested the positive sera for a potential cross reactivity with GRP peptide by competition experiments.

HUMORAL RESPONSE IN PATIENTS WITH RA AGAINST A PROTEUS PROTEIN DERIVED PEPTIDE Analysis of several immunoselected peptides from a nanopeptide phage library using serum antibodies from patients with RA had revealed a potential consensus sequence (RKAL) present in the surface membrane haemolysin of Proteus mirabilis and in the RA susceptibility sequence of the HLA-DR4 $\beta$ chain (table 2). In order to assess whether our patients with RA possessed a humoral response to Proteus mirabilis, a 16 amino acid synthetic peptide spanning the residues $27-42$ in the haemolysin protein (haem peptide: LGSISESRRALQDSQR) was made and its reactivity investigated.

\section{SYNTHETIC PEPTIDES}

Synthetic peptides (GDIA peptide: EFHELGDIAIAA; GRP peptide: GGYGDGGAHGGGYGG; haem peptide: LGSISESRRAL-

Table 1 Comparison of amino acid sequence of the GDIA peptide with potential (auto) antigens

\begin{tabular}{|c|c|c|c|c|c|c|c|c|c|}
\hline $\mathrm{H}$ & $\mathrm{E}$ & $\mathbf{L}$ & & $\mathrm{D}$ & I & A & I & A & GDIA peptide \\
\hline & G & I & I & $\begin{array}{l}\text { I } \\
\text { D }\end{array}$ & I & $\begin{array}{l}\text { I } \\
\text { A }\end{array}$ & $\dot{\vdots}$ & $S$ & $\begin{array}{l}\text { EBNA-4 nuclear protein } \\
\text { (EBV) }(920-928)\end{array}$ \\
\hline & $\mathrm{E}$ & $\begin{array}{l}\text { L } \\
:\end{array}$ & G & D & I & $\begin{array}{l}\text { A } \\
\text { I }\end{array}$ & I & A & \\
\hline & M & V & $G$ & D & I & $\mathrm{A}$ & K & $\mathbf{Y}$ & $\begin{array}{l}\text { Nucleocapsid protein } \\
\text { (Parainfluenza virus) }(246-25\end{array}$ \\
\hline & E & L & G & D & I & A & I & A & \\
\hline & E & L & $G$ & D & I & G & $\mathrm{L}$ & $\mathbf{P}$ & $\begin{array}{l}\text { Collagen type IX ( } \alpha 1 \text { chain) } \\
\text { (Human }(682-693)\end{array}$ \\
\hline & $\begin{array}{l}\text { E } \\
:\end{array}$ & & G & $\begin{array}{l}\mathrm{D} \\
\mathrm{I}\end{array}$ & I & $\begin{array}{l}\text { A } \\
\text { I }\end{array}$ & I & A & \\
\hline & D & $\mathbf{R}$ & G & D & I & A & $\mathbf{S}$ & $Q$ & $\begin{array}{l}\text { Collagen type XII ( } \alpha 1 \text { chain) } \\
\text { (Chicken) (436-444) }\end{array}$ \\
\hline
\end{tabular}

${ }^{\star}$ Immunoselected peptide containing the consensus sequence of GDIA. ${ }^{7}$ : Conserved changes.

Table 2 Comparison of the amino acid sequence of an immunoselected peptide containing the consensus sequence $R K A L^{7}$ sharing homology with a proteus protein and human $H L A$ DR4 $\beta$ sequence ${ }^{11}$

$\begin{array}{lllllllllllll}G & E & F & R & K & A & L & R & L & S & A & S^{\star}\end{array}$

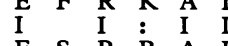

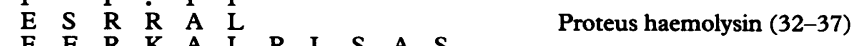

$\begin{array}{lllllllllllllllll}G & E & F & R & K & A & L & R & L & S & A & S\end{array}$

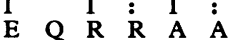

HLA-DR4ß (69-74)

* The amino acids GEF are derived from the pVIII protein

: Conserved changes.
QDSQR; control peptide: SAAPGQKVTISCSG) were synthesised and purified by high performance liquid chromatography (HPLC) by MedProbe, Oslo, Norway.

ELISA

Serum antibodies reacting with the various peptides and EPK (Sigma) were detected by ELISA. Briefly, 96 well microtitre plates were coated with $100 \mu \mathrm{l} / \mathrm{well}$ of $40 \mu \mathrm{g} / \mathrm{ml}$ peptide $(10 \mu \mathrm{g} / \mathrm{ml}$ EPK) in phosphate buffered saline (PBS) buffer. After blocking with $1 \%$ bovine serum albumin in PBS buffer for three hours at room temperature and subsequent washing, the plates were incubated with sera or SF samples ( $1 / 50$ dilution in PBS/ $0 \cdot 1 \%$ Tween 20) for one hour at $37^{\circ} \mathrm{C}$ and one hour at $4^{\circ} \mathrm{C}$. After additional washings, plates were incubated for one hour at $37^{\circ} \mathrm{C}$ with antihuman Ig alkaline phosphatase conjugated antibodies, washed again, and developed by adding p-nitrophenyl phosphate. All assays were carried out in triplicate. The reactivity of sera of patients and normal individuals to the peptides GDIA, GRP, and haem was expressed as the optical density (OD) of the response against the peptide minus the $\mathrm{OD}$ of the response against the control peptide. The competition assays with the GRP peptide and EPK were performed essentially as described previously. ${ }^{6}$ The maximum concentration of competing EPK added to GRP coated plates was $50 \mu \mathrm{g} / \mathrm{ml}$. Results were expressed as $\%$ inhibition according to the following formula:

$$
\% \text { inhibition }=100 \%(A c-A i) / A c
$$

where $A c=$ absorbance for the sera binding with no added competitor and $A i=$ absorbance for the sera binding with added competitor.

\section{STATISTICS}

Differences between the numbers of patients and controls with increased antibody reactivity were tested for significance with the nonparametric Mann-Whitney test.

\section{Results}

HUMORAL RESPONSE AGAINST AN

IMMUNOSELECTED PEPTIDE FROM A PHAGE

DISPLAY LIBRARY BY POLYCLONAL SF

ANTIBODIES

There were increased GDIA peptide specific antibodies in the SF of patients with RA (mean $=0.263$ OD units) compared with SF from OA patients (mean $=0 \cdot 114$ OD units) $(p<0.0115)$ (fig 1). In addition, there was a significant difference between the antibody reactivity to the peptide in the sera of patients with RA (mean $=0.173$ OD units) and that in normal individuals (mean $=0 \cdot 120$ OD units) $(p<0.0209)$ (fig 2).

HUMORAL RESPONSE IN PATIENTS WITH RA AGAINST A GLYCINE-RICH CELL WALL PROTEIN DERIVED PEPTIDE

There was a significant increase in antibody reactivity to the GRP peptide in the sera of 
patients with RA (mean $=0.292$ OD units) compared with normal individuals (mean = $0 \cdot 190$ OD units) ( $<<0.0001)$ (fig 3 ).

An important humoral response to EPK was found in the GRP peptide positive patients with RA; however, this response was not significantly different from that in healthy individuals $(p<0.34)$ (fig 4). EPK competed with antibodies binding to EPK coated plates, but not significantly with antibodies binding to GRP coated plates. Analysis of seven RA sera by competition experiments indicated that the
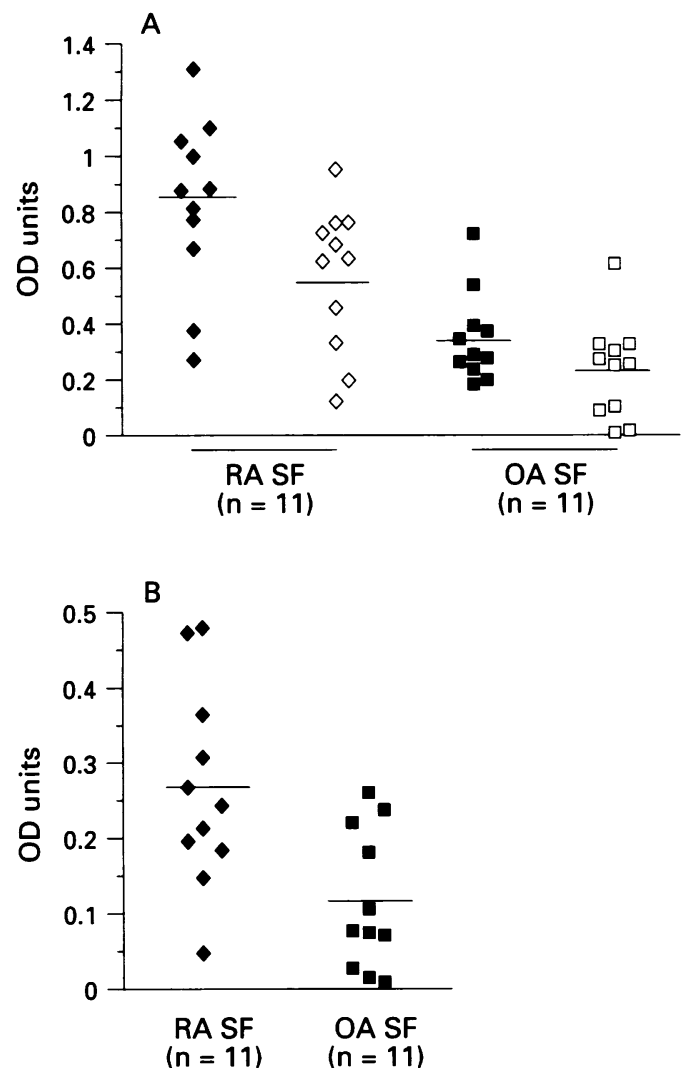

Figure 1 A: Binding of $S F$ antibodies from patients with $R A(\diamond, \diamond)$ and $O A(\square, \square)$ to GDIA peptide $(\diamond, \square)$ and control peptide $(\diamond, \square)$ coated plates. B: Binding of $S F$ antibodies from patients with $R A(\diamond)$ and $O A(\square)$ to GDIA peptide, obtained by subtracting the absorbance of the control peptide in $\boldsymbol{A}$ for each sample.

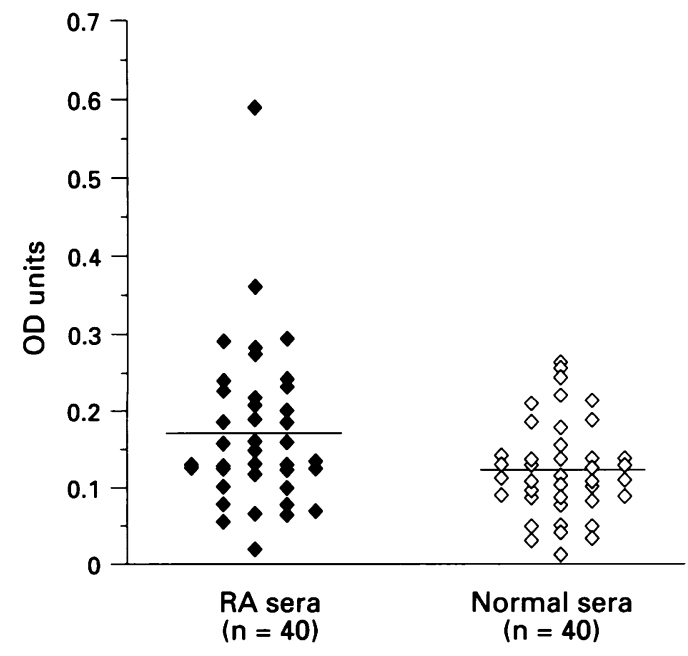

Figure 2 Binding of sera from patients with $R A(\diamond)$ and from normal controls $(\diamond)$ to the GDLA peptide, determined by subtraction as described for figure $1 B$. maximum percentage of inhibition of antibody binding GRP peptide by EPK was only $8-30 \%$ (table 3).

HUMORAL RESPONSE IN PATIENTS WITH RA AGAINST A PROTEUS PROTEIN DERIVED PEPTIDE Patients with RA had a significantly greater response to the haem peptide than normal individuals $(p<0.0011)$ (fig 5$)$, confirming the

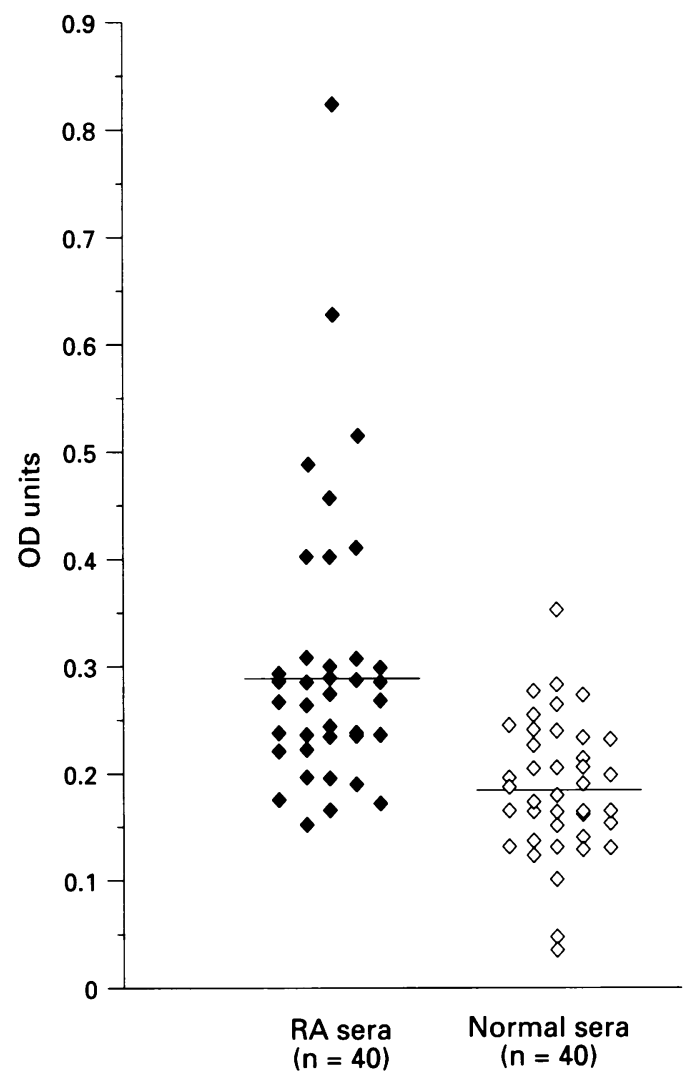

Figure 3 Binding of sera from patients with $R A(\diamond)$ and normal controls $(\diamond)$ to the GRP peptide, determined by subtraction as described in figure $1 B$.

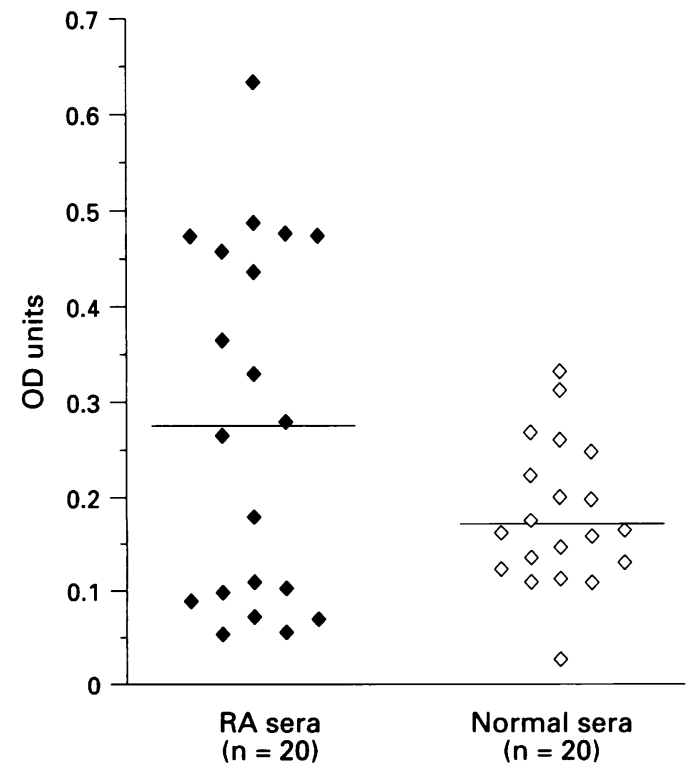

Figure 4 Reactivity of GRP peptide positive sera from patients with $R A(\diamond)$ and normal controls $(\diamond)$ to EPK, determined by subtraction as described in figure $1 B$. 
Table 3 Human epithelial keratin inhibition of the binding of antibodies in sera from patients with rheumatoid arthritis to GRP peptide coated plates

\begin{tabular}{ll}
\hline Patients & Maximum inhibition (\%) \\
\hline 1 & $30 \cdot 1$ \\
2 & $29 \cdot 7$ \\
3 & $19 \cdot 3$ \\
4 & $20 \cdot 6$ \\
5 & $8 \cdot 4$ \\
6 & $10 \cdot 4$ \\
7 & $17 \cdot 3$ \\
\hline
\end{tabular}

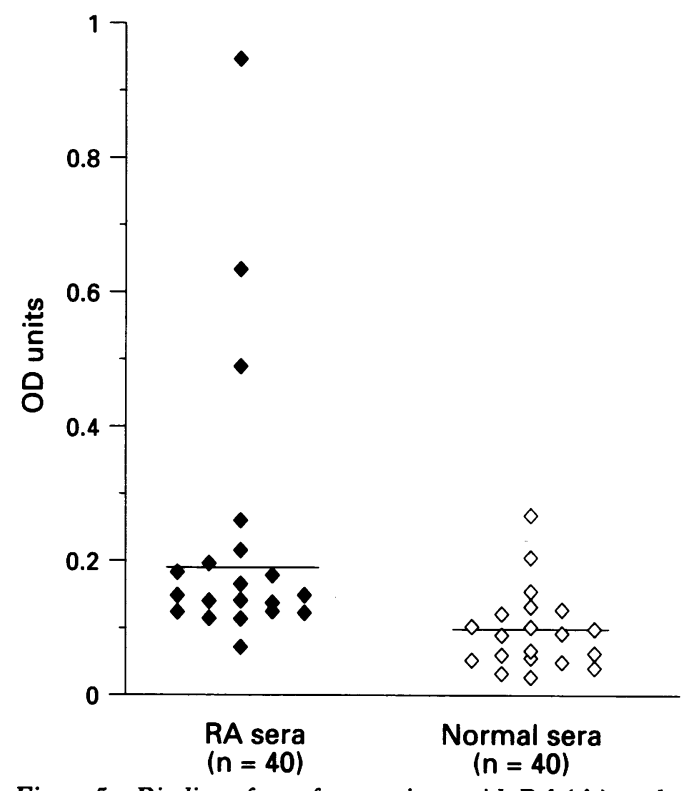

Figure 5 Binding of sera from patients with $R A(\bullet)$ and normal controls $(\diamond)$ to the haem peptide, determined by subtraction as described in figure $1 B$.

possible association of this micro-organism with RA. ${ }^{12}$

\section{Discussion}

The present study has demonstrated that motifs selected from random peptide phage libraries can be relevant for the identification of potential (auto)antigens. Indeed, we have shown that SF and sera from patients with RA contain antibodies directed against the GDIA peptide that shares $62 \cdot 5 \%$ homology with collagen type IX (table 1). The homology with the collagen type IX and XII is interesting, as anticollagen type IX antibodies have been described in patients with RA. ${ }^{13}$

Another interesting finding was the humoral response of patients with RA to GRP peptide. GRPs are ubiquitous proteins found in varying concentration in the cell walls of grains and legumes (for example kidney bean, rice, tomato). These proteins share a high homology with both type I and type II keratins (for example, $42 \cdot 1 \%$ identity in 126 amino acid overlap for EPK), the heterogeneous nuclear ribonucleoproteins (hnRNP) A1 (39\% in 200 amino acid overlap) and A2 (41\% in 144 amino acid overlap), and EBNA-1 nuclear protein (44.6\% in 451 amino acid overlap). Thus a possible cross reactivity between these proteins may exist. In this regard, at a molecular level the potential cross reactions between, for example, GRP, keratins, and
EBNA-1 could be explained by the presence of polyglycine sequences and by the glycinealanine repeats present in cytokeratins and the p62 peptide of EBNA-1. ${ }^{14-16}$ However, the failure of the EPK to compete significantly with antibodies for binding to the GRP peptide coated plate (table 3 ) demonstrates that this particular GRP epitope is not present in the native epidermal keratin proteins, thus indicating the importance of such an epitope. It is important to note that the amounts of IgA autoantibodies to cytokeratin-18 and epidermal keratin have been found to be significantly greater in patients with RA than in those with OA and normal individuals. ${ }^{17}$ In contrast, the majority of antibodies reacting with the peptides used in this study are mainly of IgG or IgM isotypes (data not shown). Furthermore, none of the peptides used in this study reacted with human monomeric IgGagarose affinity purified polyclonal rheumatoid factors, demonstrating that the antibody epitopes described are not related to rheumatoid factors.

No significant cross reactivity was found between the GRP peptide and EPK, despite the high degree of homology. This may indicate that the five amino acid difference is critical for the binding of antibodies in RA sera. In the present study, we did not have the opportunity to analyse a possible cross reactivity between antiperinuclear factor antigen(s) RA33 (hnRNP A2), and the peptides tested. However, our data provide additional information concerning potential cross reactivity, through our identification of the epitopes, as the exact epitopes of serum antibodies to perinuclear antigen(s) and RA33 are not known.

The identification of antibodies to the GRP peptide adds a novel potential external factor that may contribute to the pathology of RA and related diseases. In this context, it is possible that certain inflammatory intestinal disturbances may increase the capacity of intestinal epithelium GRP primed B or T cells to migrate into the circulation. The appearance of $T$ cells with a gut-like phenotype in the circulation and in the synovium of patients with RA, in addition to the identification in the synovium of $\mathrm{T}$ cells expressing a $\mathrm{T}$ cell receptor known to be specific for the epithelial $T$ cells of the gastrointestinal tract, ${ }^{18-21}$ supports the hypothesis that inflammatory changes in the gut may enhance the outflow of lymphocytes. ${ }^{22}$ However, additional studies are necessary to determine the extent of a possible linkage between arthritis, GRPs, and gut inflammation.

Two points are worthy of note. First, in our experimental conditions, positive sera reacted negatively with the control peptide and with at least one of the four test peptides, indicating that each serum reacted negatively with at least two peptides. Second, comparison of the primary amino acid sequence of peptides and proteins with that of other antigens may not be sufficient to identify antigenic similarities: the antibodies reacting with the synthetic peptides may not necessarily be directed at linear 
epitopes in the antigens, but could be directed at conformational epitopes.

In conclusion, the use of phage libraries offers a considerable advantage over other previously described techniques for studying (auto)antibody specificities in crude fluids from patients with autoimmune diseases. This strategy may enable the identification of potential antigens that might contribute to the breakdown of tolerance, with the subsequent generation of autoantibodies to structural proteins.

This work is supported by a grant from the Norwegian Research Council to $M$ Sioud and $A$ Dybwad, and by a grant from the Norwegian Women's Public Health Organisation. We thank David Fraser for critical reading of the manuscript.

1 Harris E D. Rheumatoid arthritis. Pathophysiology and implications for therapy. $N$ Engl f Med 1990; 322 : 1277-89.

2 Aho K, Palusuo T, Kurki P. Marker antibodies of rheumatoid arthritis: diagnostic and pathogenic reumatoid arthritis: diagnostic and pathogen

3 Hassfeld W, Steiner G, Studnicka-Benke A, et al. Autoimmune response to the spliceosome. Arthritis Autoimmune response

4 Simon M, Girbal E, Sebbag M, et al. The cytokeratin filament-aggregating protein filaggrin is the target of the socalled "antikeratin antibodies," antibodies specific for rheumatoid arthritis. F Clin Invest 1993; 92: 1387-93.

5 Venables P J W. Infection and rheumatoid arthritis. Cur Opin Rheumatol 1989; 1: 15-20.

6 Dybwad A, Førre $\varnothing$, Kjeldsen-Kragh J, Natvig J B, Sioud M. Identification of new $B$ cell epitopes in the sera of rheumatoid arthritis patients using a random nanosera of rheumatoid arthritis patients using a random nano-

7 Dybwad A, Forre $\emptyset$, Natvig J B, Sioud M. Structural characterization of peptides that bind synovial fluid characterization of peptides that bind synovial fluid
antibodies from RA patients: a novel strategy for antibodies from RA patients: a novel strategy for peptide library. Clin Immunol Immunopath 1995; 75: 45-50.

8 Arnett F C, Edworthy S M, Bloch D A, et al. The American Rheumatism Association 1987 revised criteria for the classification of rheumatoid arthritis. Arthritis Rheum 1988; 31: 315-24.
9 Østenstad B, Dybwad A, Lea T, Førre Ø, Vinje O, Sioud M. Evidence for monoclonal expansion of synovial $T$ cells bearing $V \alpha 2.1$ N 35.5 gene segments and recognizing a synthetic peptide that shares homology with a number of putative autoantigens. Immunology 1995; 86: 168-75.

10 Keller B, Sauer N, Lamb C J. Glycine-rich cell wall proteins in bean: gene structure and association of the protein with

11 Ebringer A, Cunningham P, Ahmadi K, Wrigglesworth J, Hosseini R, Wilson C. Sequence similarity between HLADR1 and DR4 subtypes associated with rheumatoid arthritis and proteus/serrratia membrane haemolysins. Ann Rheum Dis 1992; 51: 1245-6.

12 Wilson C, Ebringer A, Ahmadi K, et al. Shared amino acid sequences between major histocompatibility complex class II glycoproteins, type XI collagen and Proteus mirabilis in rheumatoid arthritis. Ann Rheum Dis 1995; 54: 216-20.

13 Morgan K, Clague R B, Collins I, Ayad S, Phinn SD, Holt P J L. Incidence of antibodies to native and denatured cartilage collagens (types II, IX, and XI) and to type I cartilage collagens (types II, IX, and XI) and to type I
collagen in rheumatoid arthritis. Ann Rheum Dis 1987; 46: collagen

14 Fuchs E, Hanukoglu E. Unravelling the structure of the intermediate filaments. Cell 1993; 1: 15-20.

15 Rhodes G, Carson D A, Valbracht J, Houghten R, Vaughan $J$ H. Human immune responses to synthetic peptides from the Epstein-Barr nuclear antigen. $₹$ Immunol 1985; 134: $211-6$.

16 Baboonian C, Venables P J W, Williams D G, Williams R O, Maini R N. Cross reaction of antibodies to a glycine/ alanine repeat sequence of Epstein-Barr virus nuclear antigen-1 with collagen, cytokeratin, and actin. Ann antigen-1 with collagen, cyto

17 Borg A A, Dawes P T, Mattey D L. Increased levels of IgA antibodies to cytokeratin-18 and epidermal keratin in rheumatoid arthritis. Arthritis Rheum 1993; 36: 229-33.

18 Sioud M, Kjeldsen-Kragh J, Quale A, et al. The Vס gene usage by freshly isolated $\mathrm{T}$ lymphocytes from synovial fluids in rheumatoid synovitis: a preliminary report. Scand f Immunol 1990; 31: 415-21.

19 Bucht A, Söderström K, Hultman T, et al. T cell receptor diversity and activation markers in the $V \gamma 1$ subset of rheumatoid synovial fluid and peripheral blood $\mathrm{T}$ lymphocytes. Eur f Immunol 1992; 22: 567-74.

20 Lazarovits A I, Karsh J. Differential expression in rheumatoid synovium and synovial fluid of $\alpha 4 \beta 7$ integrin. f Immunol 1993; 151: 6482-9.

21 Söderström K, Bucht A, Halapi E, et al. High expression of $V \gamma 8$ is a shared feature of human $\gamma \delta \mathrm{T}$ cells in the epithelium of the gut and in the inflamed synovial tissue. f Immunol 1994; 152: 6017-27.

22 O'Mahony S, Ferguson A. Small intestinal mucosal protection mechanisms and their importance in theumatology. Ann Rheum Dis 1991; 50: 331-6. 